\title{
Role of the school heads in the sustainability of zero waste management projects
}

\author{
Reodica, Carmelita \\ Emilio Aguinaldo College, Philippines (carmelitareodica.mnl@eac.edu.ph)

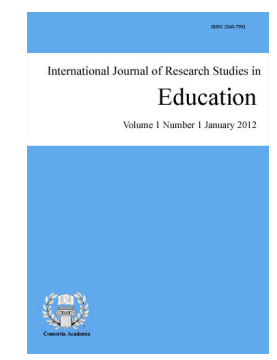

Accepted: 10 June 2021

ISSN: 2243-7703 Online ISSN: 2243-7711

OPEN ACCESS

\section{Abstract}

Zero Waste Management is a program that aimed to promote recycling and proper waste segregation among teachers, learners, parents, and other stakeholders who are considered to be responsible in the effort to protect and manage the school environment through good school governance to support sustainable development. School principals as the leader in school should be able to play an active and maximal role in the effort to create a zero-waste school. This study is aimed to find out the role of the school principal and the extent of this role in the implementation of Zero Waste Management projects. The study also can be used in other school projects amidst the existence of pandemic. This study used qualitative and quantitative methods in data collection. The investigation was done in Crisanto Guysako Memorial Elementary School of Nagcarlan, Laguna involving thirty (30) respondents that include learners, teachers, parents, and members of the community. The result of the study showed that strong agreement among the respondents was shown in the determination of the vital role of the school head in the sustainability of zero waste management program in terms of effect, empowerment, and economics. Furthermore, the results indicated that the extent of the role of school principal based on the interviews conducted on the implementation of the projects is to formulate environmental school policy; to develop eco-friendly school culture, and to ensure the sustainability of the program through the support of its stakeholders. Through the leadership of school heads, environmental awareness through orientation, assembly, and capacity building among school's stakeholders, with emphasis on issues regarding solid waste management and recycling, to encourage students and the general public to becoming environmentally responsible citizens, and to expand the knowledge and attitude towards improved practices on solid waste management.

Keywords: school heads, sustainability, zero waste management, role 


\section{Role of the school heads in the sustainability of zero waste management projects}

\section{Introduction}

Essentially, Zero Waste is a philosophy of eliminating the generation of materials that have no viable or economic option for end-of-use management. The generation of waste can be lowered through a variety of options, including reducing, reusing, recycling, or taking appropriate action to prevent waste through design and engineering solutions (Shively, 2018). Debrah et al. (2021) averred that waste is an unavoidable, unwanted material resulting from human activity. It is generated from every human and animal habitat. It is considered as the refuse of useless or worthless stuff, material to be discarded, or material that has no longer been used for any purpose by people within a specific locality, and can be classified into a solid, liquid, or gas. SW comprises sludge, garbage, refuse, and other solid materials that are discarded. It also includes SW from mining, agricultural, electronic, industrial, and municipal waste, which consists of household and commercial activities. Moreover, solid waste management is a multifaceted problem comprising political, socioeconomic, institutional, and environmental aspects. Due to exponential urban growth, it has become one of the most significant issues faced by countries. The gap in environmental knowledge among the youth and the old within developing countries contributes to ecological issues or waste management problems, resulting in unsustainable development, with important consequences in low-income countries such as the Philippines.

According to Hannon and Zaman (2018), the evolving concept and emerging practice of zero waste is a controversial sphere of discussion across urban development, manufacturing, and waste management. However, the ideal and goal of zero waste continue to be embraced by individuals, families, communities, business organizations, as well as, local municipal and national levels of government responding to the issue of waste. A significant tranche of popular, industry, and academic literature evidence how the concept of zero waste is being practically outworked and also, how this practice is evolving, as strategies, policies, and programs are implemented, "reality checked", reviewed and revised in further cycles of innovation-seeking. In response to the challenge, San Juan (2019) revealed that the participation of community members in solid waste management programs depends on the action taken by their leaders or officials. The absence of any of the resources will make a solid waste management program fail. Thus, the community members will be unsatisfied (Lad, Chauhan, \& Gole, 2020). Aside from these, mass cooperation and active participation are also necessary. Therefore, educating people through information dissemination on how to handle produced solid waste has become essential (Nolasco, Baguia, \& Padua, 2019; Baring et al., 2020).

In line with this principle, the Philippine government signed into law the Republic Act (R.A.) 9003 which is also known as the Ecological Solid Waste Management Act of 2000. The law provides the legal basis for a "systematic, comprehensive and ecological solid waste management program which shall ensure the protection of public health and environment." It mandates the creation of institutional mechanisms and strategies for the effective implementation of the solid waste management program in the country. Relevant to this idea, R.A. 9003, Section 2 mandates

\footnotetext{
"the stronger integration in the academic curricula of formal and non-formal education of ecological solid waste management and resource conservation and recovery topics to promote environmental awareness and action among the citizenry".
}

Given this context, educational institutions play a vital role in this environmental education. Their educational programs and activities are potent means to raise awareness among the members of the academic community about this pressing environmental issue and to take active roles in the protection and care of the environment, to the common home. Guided by these premises, one form of solid waste management adapted by Crisanto Guysako Memorial Elementary School of Nagcarlan, Laguna is the implementation of the Zero 
Management Program (Arjuelo, et al., 2020). Compost Bin Avenue, Basura Ko Bitbit Ko, and Globotehan are some of the projects being implemented by the school to advocate ecological education among members of its community including the learners, parents, teachers, and other stakeholders.

The first project, Compost Bin Avenue involves composting biodegradable waste in the school using ringed old roof from demolished buildings in the school which when half-filled will be added soil, organic fertilizers and serve as vegetable plant boxes. Harvested vegetables will be used to support the school feeding program. Basura Ko, Bitbit Ko uses recycled sling containers from plastic bottles. Learners put plastic wrappers from the food they eat in these containers and bring them home every after class. Sling containers were used so that learners will be able to bring them wherever they are in school.

Lastly, the Globotehan is a spherical-shaped wire container where people put used plastic bottles in school. The Zero Management Program aims to create school stakeholders including learners, parents, teachers, and the community who are responsible in the effort to protect and preserve the environment through good school administration to support sustainable development. To achieve this aim, the role of all members of the school community including the school principal is very important. School principal as a leader in school has the strategic role of the effort to create an environmentally cultured and cared for school. Based on it, this study is aimed to find out the role of school principal leadership in the implementation of the Zero Management Program as an effort to support sustainable eco-waste management.

\subsection{The objective of the study}

The aim of this study is to determine the role of school heads in the sustainability of zero waste management projects. Specifically, the study determined the vital role of the school head in the sustainability of the zero waste management program in terms of effect, empowerment, and economics. Quantitative data were gathered through the use of questionnaires. In the implementation of a school policy, the main implementer who is the essential source of decision-making is the school principal. To determine the extent of the role of the school head in the implementation of the projects, this study used a qualitative approach in gathering the data needed. Thirty (10) respondents were considered as respondents, including the learners, parents, teachers and other members of the community Respondents were randomly chosen based on their availability and willingness to participate in the study. Data collection was done through interviews using guide questions based on the extent of the role of the school heads in the implementation of Zero Waste Management projects.

\section{Methodology}

The study followed the mixed-method research design to collect data using the information gathered from the respondent's interviews and the responses from the questionnaires by the learners, parents, teachers, and other members of the community who were randomly chosen based on their availability and willingness to be involved in the study. The statements used in the questionnaires focused on the effect, empowerment, and economics of the implementation of Zero Management projects. Guide questions were prepared by the researcher for the interviews. Oral interviews were administered which intended to solicit views and observations from the respondents on the extent of the role of the school head in the implementation of Zero Waste Management projects. Quantitative data were analyzed using statistical tools such as weighted mean, verbal interpretation, and rank. Qualitative data were analyzed using content analysis; this was preceded with data processing where the data were filtered to remove irrelevant information, and unnecessary repetitions, followed by data coding.

\section{Findings, discussion implication, and recommendations}

\subsection{Findings and discussion}

The findings of the study from the data collection methods, which are presented, in the methodology section 
were synthesized in two categories. The vital role of the school head in the sustainability of the zero waste management program was determined in terms of effect, empowerment, and economics. Based on the results in terms of the effect of Zero Waste Management projects, respondents strongly agree that the school head was able to initiate and plan the guidelines of the program that those eco-friendly products were developed, solid waste and pollutants were reduced, and recycling of materials was taken into consideration and agreed that locally- sourced materials were used and natural habitat of human, plants, and animals was protected due to the implementation of the Zero Waste Management Projects.

The findings affirmed the vital role that academic institutions play in environmental education and sustainability. To sustain solid waste management or environmental issues in developing countries, formal education for sustainable development is essential at all levels of education, able to trigger a whole societal transformation. For better environmental sustainability or waste management sustainability education, teachers with the right knowledge, attitude, skills, and innovation, are required (Debrah et al., 2021). Moreover, environmental knowledge is a term used to describe concepts and behavior patterns related to the environment. Olsen et al. (2020) believe that teachers are the primary keys to develop skills of knowledge in students using education to sustain human life, sustainable environmental behavior, and achieve sustainable development. The upsurge in environmental knowledge raises the awareness of environmental problems, which may likely allow individuals to take action to protect the environment.

\section{Table 1}

Role of school head in the sustainability of zero waste management program in terms of effect

\begin{tabular}{|c|c|c|c|c|c|c|c|c|}
\hline \multirow{2}{*}{ Indicators } & \multicolumn{2}{|c|}{ Pupils } & \multicolumn{2}{|c|}{ Teachers } & \multicolumn{2}{|c|}{ Parents } & \multicolumn{2}{|r|}{ Overall } \\
\hline & WM & VI & WM & VI & WM & VI & WM & Interpretation \\
\hline \multicolumn{9}{|l|}{ Through the initiative and planning of the school head. } \\
\hline 1. Eco-friendly products were developed. & 3.60 & $\mathrm{SA}$ & 3.20 & A & 3.40 & $\mathrm{SA}$ & 3.40 & Strongly Agree \\
\hline 2. Solid waste and pollutants were reduced. & 3.60 & SA & 3.50 & SA & 3.10 & A & 3.40 & Strongly Agree \\
\hline 3. Locally- sourced materials were used. & 3.40 & SA & 3.20 & A & 3.00 & A & 3.20 & Agree \\
\hline 4. Recycling of materials was taken into consideration. & 3.40 & SA & 3.20 & A & 3.20 & A & 3.27 & Strongly Agree \\
\hline \multirow{2}{*}{$\begin{array}{l}\text { 5. Natural habitat of humans, plants, and animals was } \\
\text { protected. }\end{array}$} & 3.90 & $\mathrm{SA}$ & 3.00 & A & 3.20 & A & 3.37 & Strongly Agree \\
\hline & 3.58 & & 3.22 & & 3.18 & & 3.328 & Strongly Agree \\
\hline
\end{tabular}

Scale: $3.26-4.00$ Strongly Agree (SA), 1.76- 2.50 Disagree (D), 2.52- 3.25 Agree (A), and 1.00- 1.75 Strongly Disagree (SD).

Article 3 of the Philippine Civil Code highlights the principle "Ignorance of the law excuses no one from compliance therewith". Thus, students must know the different laws relevant to solid waste. This further implies that teachers should integrate into their lessons. Other relevant laws on solid waste management. relevant laws to include: Presidential Decree No. 825 which provides penalties for improper disposal of garbage and other forms of uncleanliness; R.A. No. 9003 the policy which mandates the state to adopt a systematic, comprehensive, and ecological solid waste management program; R.A. No. 8749 which mandates agencies to provide and integrate air quality framework; and R.A. No. 9275 mandates agencies to protect, preserve and revive fresh, brackish, and marine waters. More so, knowing the local ordinance is also essential. Schools as communities must also create guidelines in compliance and support these mandates.

As mentioned by Romero (2018), the plea to advocate zero waste in all schools has been the very call of every teacher to guarantee the safety of the learners with the imminent dangers that irresponsible garbage disposal may cause all of us. It is not only through ostentatious display of the waste prevention labels in the trash bins on garbage disposal but also their proper use towards sustainable awareness. Every school is one with the nation in the campaign of protecting our environment. The 4Rs like Reduction, Reuse, Recycling, and Recovery are explicit ways to educate the schools and the community as well in maintaining an eco-friendly environment. Through the schools' initiative to integrate this lesson in their teaching, our encouragement to help the government regarding the tons of garbage around the country is contributory to somewhat alleviate the worsening problem of eco-waste management. It is indeed true that DepEd does all viable measures to contribute to resolving this ecological impediment. 
Role of the school heads in the sustainability of zero waste management projects

In a nutshell, sustaining a program on solid waste management is dependent on the commitment of the school's leadership to ensure that an effective plan is in place and will be maintained at all times and in any way.

\section{Table 2}

Role of school head in the sustainability of zero waste management program in terms of empowerment

\begin{tabular}{|c|c|c|c|c|c|c|c|c|}
\hline \multirow{2}{*}{ Indicators } & \multicolumn{2}{|c|}{ Pupils } & \multicolumn{2}{|c|}{ Teachers } & \multicolumn{2}{|c|}{ Parents } & \multicolumn{2}{|r|}{ Overall } \\
\hline & WM & VI & WM & VI & WM & VI & WM & Interpretation \\
\hline \multicolumn{9}{|l|}{ Through the leadership of the school head. } \\
\hline $\begin{array}{l}\text { 1. The community is well-informed of the policies regarding the } \\
\text { implementation of the projects. }\end{array}$ & 4.00 & SA & 3.20 & A & 2.40 & A & 3.20 & Agree \\
\hline $\begin{array}{l}\text { 2. Participation among community members/ stakeholders was } \\
\text { solicited. }\end{array}$ & 3.50 & SA & 3.30 & SA & 3.60 & SA & 3.47 & Strongly Agree \\
\hline 3. Health of the community was taken into consideration. & 3.90 & SA & 3.70 & SA & 3.60 & SA & 3.73 & Strongly Agree \\
\hline $\begin{array}{l}\text { 4. Stakeholders were encouraged to initiate other related } \\
\text { projects. }\end{array}$ & 3.70 & SA & 3.70 & SA & 3.30 & SA & 3.57 & Strongly Agree \\
\hline \multirow[t]{2}{*}{ 5. School environment was improved. } & 3.80 & SA & 3.60 & SA & 3.60 & SA & 3.67 & Strongly Agree \\
\hline & 3.78 & & 3.50 & & 3.30 & & 3.528 & Strongly Agree \\
\hline
\end{tabular}

Scale: 3.26- 4.00 Strongly Agree (SA), 1.76- 2.50 Disagree (D), 2.52- 3.25 Agree (A), and 1.00- 1.75 Strongly Disagree (SD).

With regards to empowerment, table 2 shows that pupils, teachers, and parents strongly agreed that the school head was able to lead the program that encourages participation among community members, was solicited, community health was taken into consideration, stakeholders were encouraged to initiate other related projects, and the school environment was improved. The community is well-informed of the policies regarding the implementation of the projects earned quite a lower weighted mean than the other four indicators and was marked "agree". Education is one of the essential tools to create awareness among people, particularly in developing countries. Environmental education is, thus, essential to bridge the gap in knowledge of the young and old in waste management segregation and waste sustainability in developing countries. For Leicht et al. (2018), people's awareness about the environment and its accompanying challenges can be increased through environmental education. It develops the specified skills and expertise necessary to deal with environmental challenges and promote attitudes, motivations, and commitments to form decisions and take responsible actions.

Since school is one of the avenues that will provide education and will disseminate information about solid waste management, several studies were conducted in determining its impact on the student's level of awareness and practices. Molina and Catan (2021) cited that students' solid waste management practices in terms of segregation, reduce and recycle were good; while their practices in terms of recycling and disposal were fair. The awareness on solid waste management of the students did not influence their practices in disposal however had affected their practices specifically on segregation, reduction, reuse, and recycle. Molina and Catan (2021) also cited that waste collection got the highest composite mean particularly on the promotion of 3Rs (Reduce, reuse, recycle) while waste recycling and waste treatment obtained the lowest composite mean. It can be seen in table 3 that the respondents strongly agree in terms of economics, the school head was able to plan that the projects required a minimal amount to be implemented, and the funds raised were used to support other school projects. While generally, they agreed that incentives were given to stakeholders who sustain the practices, funds were generated from the projects, and water and electrical energy were conserved.

Cook (2020) mentioned the economic, social, and environmental benefits associated with building a solid waste management program. Many recyclable materials are valuable enough to sell and be reused. This not only promotes a circular economy but also creates a potential for cost savings from recycling. Recycling helps to reduce the pollution caused by waste as harmful chemicals and greenhouse gasses are often released from plastics and other recyclable materials in landfill sites. Recycling reduces the need for raw materials so that the rainforests can be preserved, allowing natural habitats to remain safe. Large amounts of energy are used when making products from raw materials. Recycling requires much less energy and therefore helps to preserve natural resources. Zero waste derives from the perception that waste must be understood as a potential resource. Thus, in the practices oriented by this philosophy, wastes are values to be realized and not problems to be solved (Allam, 2018).

Solid waste management sustainability or environmental sustainability barriers can be overcome in schools 
Reodica, C.

when governments and other agencies can financially support sustainability projects in schools, train teachers to improve on sustainability knowledge, aiming to enhance the cleaner production effectiveness. Schools are formulating curricula to promote sustainability through practice, awareness, and involvement, leading to sustainable development and cleaner and greener production. Accordingly, through efficient zero waste management, income-generating projects can be possible for schools. School heads and other stakeholders may come up with plans on how to turn the waste from school to income which may be directed to other school's programs and projects.

Table 3

Role of school head in the sustainability of zero waste management program in terms of economics

\begin{tabular}{|c|c|c|c|c|c|c|c|c|}
\hline \multirow{2}{*}{ Indicators } & \multicolumn{2}{|c|}{ Pupils } & \multicolumn{2}{|c|}{ Teachers } & \multicolumn{2}{|c|}{ Parents } & \multicolumn{2}{|r|}{ Overall } \\
\hline & WM & VI & WM & VI & WM & VI & WM & Interpretation \\
\hline \multicolumn{9}{|l|}{ Through the planning of the school head. } \\
\hline $\begin{array}{l}\text { 1. Implementation of the projects requires minimal or zero } \\
\text { amount. }\end{array}$ & 3.70 & SA & 3.50 & SA & 3.60 & A & 3.6 & Strongly Agree \\
\hline $\begin{array}{l}\text { 2. Incentives were given to stakeholders who sustain the } \\
\text { practices. }\end{array}$ & 2.70 & A & 2.80 & A & 3.50 & A & 3.0 & Strongly Agree \\
\hline $\begin{array}{l}\text { 3. Funds were generated through the implementation of the } \\
\text { projects. }\end{array}$ & 3.40 & SA & 3.20 & A & 3.30 & A & 3.33 & Strongly Agree \\
\hline $\begin{array}{l}\text { 4. Funds generated were used to support other school } \\
\text { projects for continuous improvement. }\end{array}$ & 3.90 & SA & 3.30 & SA & 3.40 & SA & 3.50 & Strongly Agree \\
\hline \multirow{2}{*}{$\begin{array}{l}\text { 5. Water and electrical energy were conserved through the } \\
\text { projects. }\end{array}$} & 3.60 & SA & 3.00 & A & 3.20 & A & 3.30 & Strongly Agree \\
\hline & 3.46 & & 3.16 & & 3.40 & & 3.186 & Strongly Agree \\
\hline
\end{tabular}

The extent of the role of the school principal based on the interviews is to formulate environmental school policy; to develop eco-friendly school culture and to ensure the sustainability of the program through the support of its stakeholders. Respondents observed that in the initial step, the school formed a Technical Working team for the Zero Management projects which consist of teachers and selected parents. Zero Management Team is led by a program coordinator and appointed by the school head. Based on the finding of the result, the team is led by a teacher and the school principal has the role of consultant of the team. In the implementation of Zero Management projects, the school principal has a role to arrange the planning, organization, supervision, organization, and evaluation of the program.

The school head leads the formulation of the school policy. It is important to note that the commitment of the school leader is vital to the effort of conceptualizing the guidelines in ensuring the effectiveness and success of a school program. Based on the responses of the participants of the study, the school head has a high commitment towards the realization of a program that could address the ecological waste challenges of the school. Responses indicated that the guidelines presented by the school head were effectively clarified and well-discussed to the stakeholders of the school. The study of Debrah et al. (2021) sought to establish that teachers' environmental knowledge influences how waste is practiced and managed in schools. Most teachers in developing countries lack practical environmental knowledge to impact positive environmental education in students, which will contribute to enhancing environmental sustainability. It must be highlighted that the developing countries do not have the facilities and technologies for practical studies of sustainable waste management. It can be concluded that teachers and school leaders play essential roles in environmental education and sustainability, and these roles help to transform schools and society as a whole.

In connection with this, as an innovator, the school principal should implement renewals of education implementation in the school. The school principal also should always supervise learning activities done by teachers, to make sure that they apply various approaches, strategies, methods, and learning techniques which involve students actively, and develop local issues in learning about the environment (Desfandi et al., 2017). By immediately involving the stakeholders of the school, the school head was able to gather the support of the teachers, parents, learners, and members of the community. It is important to note that through the influence of stakeholders of the school, more engagement can be expected from the community and not only the school. Because of this, the

62 Consortia Academia Publishing (A partner of Network of Professional Researchers and Educators) 
responses of the participants of the study indicated the development of eco-friendly culture and created awareness on the importance of a clean, safe and beautiful environment as embodied in the Zero Waste Management projects.

The school principal should always advocate teachers to be able to raise the local environmental issue and problem in learning and relate it with learning material, as an effort to make learning close with the local condition while train students to overcome environmental problems that occurred in the surrounding environment (Desfandi et al., 2017). Teachers' education has a significant role in the processes of sustainability, according to Nousheen et al. (2020). Students showed positive attitudes and awareness of environmental issues, active participation, or the practice of environmental education, which leads to environmental sustainability programs, such as conservation and protection of the environment as well as recycling, which are not always available in developing countries.

The paper of Madrigal and Oracion (2017) assesses the solid waste management awareness, attitude, and practices of the employees and students. The major findings of the study show that the respondents demonstrated a very high level of awareness and attitude and a high extent of the practice of solid waste management. A significant difference was found in the awareness, attitude, and practices of respondents when they were grouped according to status and religion. Also, the findings established the relationship between awareness and attitude on one hand and the extent of the practice of solid waste management. Awareness, attitudes, and practices were significantly related to age and educational level, except for sex which showed no correlation with attitude and practices. Generally, this paper validates how knowledge influences attitude that subsequently determines behavior, particularly in solid waste management as intervened by appropriate environmental education.

A cross-sectional survey was conducted by Barloa et al. (2016) to capture the knowledge, attitude, and practices on solid waste management. While most students had satisfactory levels for knowledge and attitude on SWM-related matters, less than half, showed satisfactory practice level. Similarly, the relatively higher average rating for knowledge and attitude of the students were both inconsistent with the lower average practice rating. The average practice rating was, with merely half having satisfactory practice ratings. The interaction effect between knowledge and attitude ratings significantly predicted the students' practice rating. This reflects that eco-school programs give a big influence on students' knowledge but do not give a significant influence on students' attitudes and behavior. Through the awareness of the learners, parents, teachers, and other stakeholders of the school, the school head was able to guide and supervise the implementation of the program. The great attention given by the school head which arises from the commitment to the success of the program motivated the members of the community and the school stakeholders to support and sustain the projects.

In the Philippines, solid waste management is gaining importance given the increase in solid waste generation caused by rapid urbanization and population growth. In the study of Matsumoto and Saizen (2017), interviews were conducted to evaluate the educational benefits produced by the school eco-centers. The results showed that the students in the model school practiced proper segregation and had a sense of responsibility which affected the students' littering behavior and waste segregation. In addition, the research found that the activity of the school eco-center, together with the "Eco-waste sa Eskwela" school waste education program provided students, teachers, and parents with the opportunity of practicing proper segregation, and also provided schools with economic benefits from managing recyclable waste. In the effort to build eco-friendly school culture, the role of a school principal is very important.

Based on the finding of the study of Desfandi et al. (2016), the school principal had not played a role as a model and motivator maximally in school. This is based on the indicator that all school principals do not every day supervise the environmental behavior of all school members. This condition is a result of their business and lack of motivation to build eco-friendly school culture. This is why the school culture which is built in all schools studied has not been strong. The change of school culture should be started from school principal leadership. Therefore, school principals in EcoSchool should be aware of the importance of building an eco-friendly school culture and should be aware that this is not detached from the structure and pattern of their leadership style. 


\section{Implication and recommendations}

The role of the school principal in the implementation of a zero-waste management program is very important and strategic. The school principal should be able to play a role maximally in the effort to embody the program, that is, a school that cares about the environment and has environmental culture, as a result of the school principal's commitment and care toward environmental problems. Therefore, all school principals should have the awareness that the problem is the responsibility of all individuals and institutions, including educational institutions. In the global environment which is in a crisis condition, a school should be able to play a role in preserving and managing the environment which begins from the school environment as an effort to support sustainable development from the local level. Then the school principal should become a guidance, role model, and motivator for all subordinates and students in the effort to embody the environmental culture and caring school.

Schools must have a tough stance on an advocacy campaign for zero waste management. The integration of 4Rs in their lessons tacitly impacts awareness and commitment to saving and protecting our environment. The use of harmful chemicals in schools is discouraged to maintain a child-friendly environment. The plastic-free campaign is a powerful tool to platform relevant information to learners on the significance of having a clean environment in the school which begins in the homes. By involving parents as well, they are likely sharing commitment and liability on this campaign.

Relative to this, while students first learn at home, which generally means parents should set an example for their children in many aspects of life, it can be the other way around, particularly in terms of caring for the environment. Students may be tasked to watch over their parents' compliance with cleanliness measures, including garbage disposal, segregation, and reduction. Waste Management Program, which has been integrated into the schools' homeroom class as part of the students' elective subjects. The problem of garbage reduction is not confined within a particular city or community, it is also important at home, where students and parents at home play a very vital role (Caliwan, 2020).

The commitment of the school head, teachers, learners, parents, and community are warranted in the advocacy campaign to zero waste management which has been a long time wake-up call by Republic Act (RA) 9003 also known as the Ecological Solid Waste Management Act 2000. This law was crafted in compliance with the alarming effects of the uncontrolled disposal of waste in our environment that poses impending dangers in our health and most especially in our ecosystem. Moreover, school officials should institutionalize collaboration so that when this pandemic is over, the culture of joining together hand-in-hand would continue for the continuous progress of education. Collaboration should not be a one-time project or program but a system that needs to be embraced whatever the mode of learning is being implemented (Pascual, 2020).

School heads should live up to the challenging times by continually improving and implementing their school's learning continuity plan as the pandemic in the community still prevails. District Supervisors should continue to provide technical assistance and professional advice to school heads under their care. Cheering school leaders up and providing moral support is a must need action from them so as school leaders would not feel they are alone in rowing the boat. Regular district feed-backing can be done to highlight best practices wherein schools can adapt and implement in their context (San Miguel, 2021).

Thus, the schools are indeed taking practical actions in their simplest ways through sustainable programs and projects, proper waste disposal, and partnership with LGU to help and resolve the looming problems on waste management. The waste prevention techniques are integrative as reminders to the learners of a solid commitment to the zero-waste management campaign of DepEd and the government as a whole. The school stakeholders' commitment is as vital as the testament to promote sustainability awareness to save and protect the environment for the next generation to enjoy. 


\section{Conclusion}

Strong agreement among the respondents was shown in the determination of the vital role of the school head in the sustainability of the zero waste management program in terms of effect, empowerment, and economics. Furthermore, the results indicated that the extent of the role of school principal based on the interviews conducted on the implementation of the projects is: (1) to formulate environmental school policy; (2) to develop eco-friendly school culture (3) to ensure the sustainability of the program through the support of its stakeholders. Through the leadership of school heads, environmental awareness through orientation, assembly, and capacity building among school's stakeholders, with emphasis on issues regarding solid waste management and recycling, to encourage students and the general public to become environmentally responsible citizens, and to expand the knowledge and attitude towards improved practices on solid waste management.

\section{References}

Arjuelo, G., Mojado, L. J., \& Francia, R. E. (2020). Sustainability of zero waste management projects of CGMES. Paper Presented to SDO-Laguna.

Baring, R., del Castillo, F., \& Guanzon, M. (2020). Climate change and service learning in light of "Laudato Si": reviewing educators' perceptions. The International Journal of Climate Change: Impacts and Responses 12(1), 1-12. https://doi.org/10.18848/1835-7156/CGP/v12i01/1-12

Caliwan, C. L. (2020). Program prods students to teach parents on waste management. Retrieved from https://www.pna.gov.ph/articles/1092409

Cook, K. (2020). The positive impacts of implementing a successful waste management program at your amusement park. Retrieved from

https://www.buschsystems.com/blog/blogs/the-positive-impacts-of-implementing-a-successful-waste-m anagement-program-at-your-amusement-park/

Debrah, J. K., Vidal, D. G., \& Dinis, M. A. P. (2021). Raising awareness on solid waste management through formal education for sustainability: A developing countries evidence review. Recycling, 6(6). https://doi.org/10.3390/recycling6010006

Lad, D., Chauhan, R., \& Gole, P. (2020). A study on solid waste management awareness amongst youngsters of Mumbai. EPRA International Journal of Multidisciplinary Research, 6(3), 116-119. https://doi.org/10.36713/epra4115

Leicht, A., Heiss, J., \& Byun, J. W. (Eds.) (2018). Issues and trends in education for sustainable development. UNESCO: Paris, France.

Molina, R. A.., \& Catan, I. (2021). Solid waste management awareness and practices among senior high school students in a State College in Zamboanga City, Philippines. Academia, 5(1), 21001. https://doi.org/10.21601/aquademia/9579

Nolasco, M., Beguia, Y., \& Padua, M. L. (2019). Solid waste management in Naga City: Its culture of information dissemination. Asia Pacific Journal of Multidisciplinary Research, 7(4), 12-17.

Pascual, E. A. (2020). Parent-teacher-learner collaboration in modular distance learning. LAP Lambert Academic Publishing: Mauritius.

Republic Act RA (9003) Ecological Solid Waste Management Act of 2000. Retrieved from https://www.officialgazette.gov.ph/2001/01/26/republic-act-no-9003-s-2001/

Romero, G. L. (2018). Advocating zero waste in schools. Sun Star Pampanga. Retrieved from https://www.pressreader.com/philippines/sunstar-pampanga/20180726/281694025574909

San Juan, F. (2019). Community participation in solid waste management program of selected community associations in Zamboanga City, Philippines. Asia Pacific Journal of Multidisciplinary Research, 7(4), 42-49.

San Miguel, N. V. (2021). School leaders' resilience amidst pandemic. LAP Lambert Academic Publishing. Shively, O. (2018). What is zero waste? Retrieved from https://mediaroom.wm.com/what-is-zero-waste/ 
Reodica, C.

66 Consortia Academia Publishing (A partner of Network of Professional Researchers and Educators) 